\title{
INFLUÊNCIA DA ATMOSFERA MODIFICADA POR FILMES PLÁSTICOS SOBRE A GUALIDADE DO MAMÃO ARMAZENADO SOB REFRIGERAÇÃO ${ }^{1}$
}

\author{
Luciana Konda de Azevedo PINTO ${ }^{2}$, Meire Lelis Leal MARTINS ${ }^{2}$, Eder Dutra de RESENDE ${ }^{2 *}$, \\ Robson Ferreira de ALMEIDA², Letícia VITORAZI², Sílvia Menezes de Faria PEREIRA²
}

\begin{abstract}
RESUMO
A utilização de embalagens constitui uma ferramenta importante no armazenamento de frutas. Neste trabalho foi avaliado o efeito dos filmes plásticos, Xtend ${ }^{\circledR}$ e PEBD, sobre a conservação do mamão. Frutos de mamoeiro "Golden", apresentando de 10 a $15 \%$ de coloração amarela na casca, após passarem por tratamentos térmicos e químicos, foram embalados individualmente e armazenados por 32 dias a $10^{\circ} \mathrm{C}(90-95 \%$ UR). Frutos sem embalagem serviram de controle. Durante o período de armazenamento foram avaliadas as características de perda de massa, firmeza, sólidos solúveis totais, acidez titulável, pH, a razão SST/AT e a quantidade relativa de $\mathrm{CO}_{2}$ no interior das embalagens. Os resultados mostraram que os frutos embalados com o filme Xtend ${ }^{\circledR}$ apresentaram menor acúmulo de $\mathrm{CO}_{2}$ do que os frutos embalados com PEBD. Entretanto, a perda de massa foi minimizada pelo filme de PEBD, evitando o enrugamento da superfície durante os 32 dias de estocagem a $10{ }^{\circ} \mathrm{C}$. Os dois tipos de filmes suprimiram o aumento de SST nos frutos ao final da estocagem, minimizando também a concentração de ácidos orgânicos. Os frutos embalados com o filme Xtend ${ }^{\circledR}$ apresentaram os maiores valores da razão SST/AT devido ao menor conteúdo final de acidez e de sólidos solúveis totais.
\end{abstract}

Palavras-chave: Carica papaya, embalagem, composição química, respiração.

\section{SUMMARY}

INFLUENCE OF A MODIFIED ATMOSPHERE BY PLASTIC FILM ON THE QUALITY OF PAPAYA FRUIT STORED IN A REFRIGERATOR. The use of plastic packaging is an important tool for storing fruit. The aim of this work is to evaluate the effect of plastic film, Xtend ${ }^{\circledR}$ and PEBD on preserving papaya. Papaya fruit cv "Golden", showing 10 to $15 \%$ of yellowish peel and also having had chemical and thermal treatments, were wrapped individually in film and stored for 32 days at $10{ }^{\circ} \mathrm{C}(90-95 \%$ UR). Fruit without packaging served as a control. Throughout the storage period, the characteristics of mass loss, firmness, total soluble solids, titratable acidity, pH, SST/AT ratio and the relative amount of $\mathrm{CO}_{2}$ inside the packaging were evaluated. Results showed that fruit wrapped in Xtend ${ }^{\circledR}$ film presented lower $\mathrm{CO}_{2}$ accumulation than those stored in PEBD film. However, the mass loss was minimized by using PEBD film, also avoiding wrinkles on the surface of the fruit up to 32 days of storage at $10^{\circ} \mathrm{C}$. Both types of film suppressed the SST and organic acid accumulation in the fruit at the end of storage. The papaya wrapped in Xtend ${ }^{\circledast}$ film presented a higher SST/AT ratio due to the final lower acidity and SST concentration.

Keywords: Carica papaya, packaging, chemical composition, respiration.

\section{1 - INTRODUÇÃO}

O mamão (Carica papaya L.) é um fruto climatérico que apresenta alta taxa respiratória e produção de etileno após a colheita [15]. Estas características lhe conferem alta perecibilidade quando estocados em condições ambientais. Desta forma, o controle do amadurecimento é fundamental para o aumento da vida após a colheita, principalmente quando se visa atender aos mercados mais distantes.

Um aumento da vida útil de frutas pode ser obtido pelo uso de filmes plásticos flexíveis, que agem como embalagem de atmosfera modificada [1]. Esta técnica utilizada como um suplemento da refrigeração promove o abaixamento da taxa de respiração pelo aumento do nível de $\mathrm{CO}_{2}$ e decréscimo do nível de $\mathrm{O}_{2}$ [21]. Além disso, minimiza a perda de água [6],

\footnotetext{
${ }^{1}$ Recebido para publicação em 19/05/2005. Aceito para publicação em 20/10/2006 (001530)

${ }^{2}$ Laboratório de Tecnologia de Alimentos (LTA),

Centro de Ciência e Tecnologia Agropecuária (CCTA),

Universidade Estadual do Norte Fluminense (UENF),

Av. Alberto Lamego, 2000, Bairro Parque Califórnia, CEP 28013-602,

Campos dos Goytacazes (RJ), Brasil,

E-mail:eresende@uenf.br

* A quem a correspondência deve ser enviada
}

o crescimento microbiano [9] e retarda a deterioração enzimática [12].

Filmes poliméricos com diferentes permeabilidades aos gases são atualmente empregados para as embalagens de atmosfera modificada (EAM) [16]. Um dos fatores mais importantes a ser considerado durante o projeto da EAM é a seleção do filme, cuja permeabilidade a diferentes gases ajuda a regular as trocas gasosas durante a estocagem do produto. Entretanto, a EAM é apenas uma técnica suplementar para condições ótimas de temperatura e umidade, uma vez que qualquer mudança no ambiente de estocagem pode elevar a taxa de respiração para níveis perigosos, resultando na deterioração do produto [21].

O polietileno de baixa densidade (PEBD) é um dos filmes que têm sido utilizados como EAM. Ele apresenta permeabilidade seletiva aos gases emitidos durante a estocagem de frutos e minimiza também a transpiração [8, 10, 11]. Além disso, outros filmes têm sido desenvolvidos para a aplicação na pós-colheita de frutos, como o Xtend ${ }^{\circledR}$, utilizado na conservação de manga [18], goiaba [23], nectarina e laranja [20].

Neste contexto, o presente trabalho foi desenvolvido com a finalidade de avaliar o efeito da modificação da atmosfera 
por embalagens com filmes plásticos PEBD e Xtend ${ }^{\circledR}$, sobre as características físicas, químicas e respiração de frutos de mamoeiro cv. Golden, mantidos sob condições de estocagem refrigerada. Esta variedade tem grande participação na pauta de exportação nacional e também no mercado interno, necessitando de maior conhecimento de seu comportamento pós-colheita.

\section{2 - MATERIAL E MÉTODOS}

Os frutos de mamoeiro cv Golden foram selecionados na linha de embalagem da Caliman Agrícola S.A. (Linhares-ES), em Janeiro/03, após tratamentos térmicos $\left(48{ }^{\circ} \mathrm{C} / 20 \mathrm{~min}\right)$ e imersão em banho fungicida ( $2 \mathrm{~min}$ ), apresentando de 10-15\% de coloração amarela na casca. Posteriormente, foram mantidos em câmara fria a $10{ }^{\circ} \mathrm{C}$ e transportados sob refrigeração para o Laboratório de Tecnologia de Alimentos (LTA/CCTA) da Universidade Estadual do Norte Fluminense Darcy Ribeiro, onde os experimentos foram conduzidos, aproximadamente 24 h após a colheita.

Os mamões foram embalados individualmente em filmes plásticos medindo $20 \mathrm{~cm}$ de comprimento e $20 \mathrm{~cm}$ de largura e selados com Seladora a Vácuo AP 450. Os filmes utilizados foram copolímeros laminados produzidos pela StePac L. A. Ltda, Israel, com nomes comerciais de Xtend ${ }^{\circledR}$ 815-PP7 (28 $\mu \mathrm{m}$ de espessura, difusividade ao $\mathrm{O}_{2}$ de $3,5 \mathrm{x}$ $10^{-10} \mathrm{~cm}^{2} / \mathrm{s}$ e difusividade ao $\mathrm{CO}_{2}$ de $\left.5,3 \times 10^{-10} \mathrm{~cm}^{2} / \mathrm{s}\right)$, e o Polietileno de Baixa Densidade PEBD (30 $\mu \mathrm{m}$ de espessura, difusividade ao $\mathrm{O}_{2}$ de $1,68 \times 10^{-7} \mathrm{~cm}^{2} / \mathrm{s}$ e difusividade ao $\mathrm{CO}_{2}$ de $2,8 \times 10^{-8} \mathrm{~cm}^{2} / \mathrm{s}$ ). As difusividades dos filmes foram determinadas utilizando-se um analisador de gás infravermelho do LCFIS-CCT/UENF (URAS 14, HARTMANN \& BRAUN).

Depois de embalados, os frutos foram armazenados em incubadoras (BOD), marca Marconi, modelo MA 415, à temperatura de $10^{\circ} \mathrm{C}$ e $85-95 \%$ UR. Em intervalos de quatro dias, cinco frutos por tratamento foram retirados aleatoriamente das incubadoras, para a realização das análises físicas, químicas e de respiração. Frutos sem embalagem foram utilizados como controle.

As análises foram feitas na metade externa do mesocarpo do fruto, pois apresenta características físicas e químicas distintas da parte mais interna, possibilitando, portanto, uma menor dispersão nos resultados [22].

O conteúdo de sólidos solúveis totais (SST) foi determinado com um refratômetro digital ATAGO modelo PR 201. Os resultados foram expressos em ${ }^{\circ} \mathrm{Brix}$. A acidez titulável (AT) foi determinada em percentagem (\%) de ácido cítrico, após diluição da amostra (5 g) em $150 \mathrm{~mL}$ de água destilada

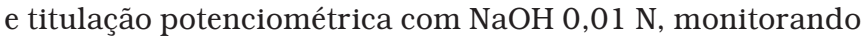
o ponto de viragem do indicador em $\mathrm{pH} \mathrm{8,1,} \mathrm{conforme} \mathrm{o}$ método da AOAC [4]. O pH foi medido com pHmetro WTW Modelo 330, após imersão direta do eletrodo na solução. A razão SST/AT foi obtida pela relação entre o conteúdo de sólidos solúveis totais (SST) e a acidez titulável (AT).

As medidas de firmeza da polpa foram realizadas com o auxílio de um penetrômetro digital, marca TR TURONI-Italy, modelo 53205, com sonda de $8 \mathrm{~mm}$ de diâmetro. Os frutos foram cortados transversalmente na região equatorial, e as leituras realizadas em quatro pontos eqüidistantes do mesocarpo na parte mais externa. Estas medidas avaliaram a força de ruptura da polpa, sendo expressas em Newton (N).

Para a determinação da perda de massa, os frutos foram pesados no início do experimento utilizando-se uma balança de precisão semi-analítica marca Gehaka, modelo BG 2000. Posteriormente, em cada intervalo de amostragem, a perda de massa fresca foi monitorada, sendo os resultados expressos em percentagem de redução de massa, normalizados para $100 \mathrm{~g}$ do fruto.

A avaliação do acúmulo de $\mathrm{CO}_{2}$ no interior da embalagem foi obtida por meio da medida da quantidade relativa do gás, utilizando como estado de referência um padrão de $\mathrm{CO}_{2}$ igual a $512 \mathrm{ppm}$. Amostras de ar (1 mL) foram retiradas com uma seringa hermética através de um septo de silicone colocado na superfície da embalagem. As análises foram realizadas em cromatógrafo a gás Shimadzu GC-14B, utilizando-se o hélio como gás de arraste a uma vazão de $12 \mathrm{~mL} / \mathrm{min}$ (fluxo de referência) e $48 \mathrm{~mL} / \mathrm{min}$ (fluxo do carreador), com pressão do carreador primário e secundário de $400 \mathrm{kPa}$ e $165 \mathrm{kPa}$, respectivamente. A coluna (empacotada Porapak Q) e o injetor foram mantidos à temperatura de $100{ }^{\circ} \mathrm{C}$, e o detector de condutividade térmica a $150{ }^{\circ} \mathrm{C}$, operando com uma corrente de $100 \mathrm{~mA}$ (TCD). Os resultados foram expressos em quantidade relativa de $\mathrm{CO}_{2}$, com relação ao padrão de 512 ppm de $\mathrm{CO}_{2}$, contido em $1 \mathrm{~mL}$ do ar da embalagem [19].

O delineamento experimental adotado foi o inteiramente casualizado, em esquema fatorial $3 \times 8$. Os fatores estudados foram 3 tratamentos com embalagens (Xtend ${ }^{\circledast}$, PEBD e Controle) e 8 períodos de armazenamento, com 5 repetições. Os resultados foram submetidos à análise de variância e as médias comparadas pelo teste de Tukey, ao nível de $5 \%$ de probabilidade.

\section{3 - RESULTADOS E DISCUSSÃO}

Os frutos embalados com o filme PEBD apresentaram um aumento da quantidade relativa de $\mathrm{CO}_{2}$ após oito dias de armazenamento (Tabela 1). Esse aumento também ocorreu para os frutos armazenados em filme Xtend ${ }^{\circledR}$, tendo atingido o valor máximo no décimo segundo dia. Os resultados mostraram também que a embalagem com PEBD possibilitou uma redução posterior da quantidade relativa de $\mathrm{CO}_{2}$ após os 26 dias de estocagem. Os frutos embalados com o filme Xtend ${ }^{\circledR}$ apresentaram uma diminuição dos valores aos 16 dias de estocagem. Estes resultados são similares aos de GONZÁLEZ-AGUILAR, BUTA \& WANG [8], que observaram uma rápida acumulação de $\mathrm{CO}_{2}$ durante os 7 primeiros dias de estocagem de mamões cv. Sunrise mantidos a $10{ }^{\circ} \mathrm{C}$ sob atmosfera modificada com PEBD.

De acordo com a Tabela 1, os frutos embalados com o filme PEBD mostraram maior acúmulo de $\mathrm{CO}_{2}$ do que aqueles embalados com o filme Xtend ${ }^{\circledR}$. O Filme PEBD tem difusividade ao $\mathrm{O}_{2}\left(1,68 \times 10^{-7} \mathrm{~cm}^{2} / \mathrm{s}\right)$ maior que a difusividade ao $\mathrm{CO}_{2}\left(2,8 \times 10^{-8} \mathrm{~cm}^{2} / \mathrm{s}\right)$ o que é favorável à respiração 
TABELA 1 - Médias da quantidade relativa de $\mathrm{CO}_{2}$ em embalagens de mamão "Golden" com os filmes Xtend ${ }^{\circledast}$ e PEBD, estocados a $10^{\circ} \mathrm{C}$.

\begin{tabular}{cccccccc}
\hline Embalagens & \multicolumn{7}{c}{ Período de armazenamento (dias) } \\
\cline { 2 - 8 } & $\mathbf{4}$ & $\mathbf{8}$ & $\mathbf{1 2}$ & $\mathbf{1 6}$ & $\mathbf{2 0}$ & $\mathbf{2 6}$ & $\mathbf{3 2}$ \\
\hline Xtend $^{\circledR}$ & $0,48 \mathrm{c}$ & 1,27 c & 1,61 a & 1,57 a & 1,09 b & $1,20 \mathrm{~b}$ & $0,79 \mathrm{c}$ \\
PEBD & $1,02 \mathrm{~b}$ & 2,40 a & 2,05 ab & 1,59 ab & 2,51 a & 2,57 a & $1,07 \mathrm{~b}$ \\
\hline
\end{tabular}

As médias seguidas de, pelo menos, uma mesma letra na linha não diferem entre si ao nível de $5 \%$ de probabilidade pelo teste de Tukey.

e concentração dos gases. Além disso, o filme PEBD apresentou valores de difusividade, tanto ao $\mathrm{O}_{2}$ quanto ao $\mathrm{CO}_{2}$, com uma ordem de magnitude muito superior aos valores de difusividade do filme $\mathrm{Xtend}^{\circledR}\left(3,5 \times 10^{-10} \mathrm{~cm}^{2} / \mathrm{s}\right.$ ao $\mathrm{O}_{2}$ e $5,3 \mathrm{x}$ $10^{-10} \mathrm{~cm}^{2} / \mathrm{s}$ ao $\mathrm{CO}_{2}$ ). Ressalta-se também que o filme PEBD apresentou maior espessura do que o Xtend ${ }^{\circledR}$, contribuindo para a maior retenção de $\mathrm{CO}_{2}$ na embalagem.

A perda de massa dos frutos do tratamento do controle foi de $9,17 \%$ ao final do período de armazenamento (Tabela 2). Para aqueles frutos embalados com os filmes Xtend $^{\circledR}$ e PEBD, a perda de massa foi de 6,24 e $0,31 \%$, respectivamente.

TABELA 2 - Médias da perda de massa (\%) em mamões "Golden" acondicionados em dois filmes (Xtend ${ }^{\circledast}$, PEBD) e dos frutos não embalados (controle) em diferentes períodos de armazenamento a $10{ }^{\circ} \mathrm{C}$.

\begin{tabular}{ccccccccc}
\hline Embalagens & \multicolumn{7}{c}{ Período de armazenamento (dias) } \\
\cline { 2 - 9 } & $\mathbf{0}$ & $\mathbf{4}$ & $\mathbf{8}$ & $\mathbf{1 2}$ & $\mathbf{1 6}$ & $\mathbf{2 0}$ & $\mathbf{2 6}$ & $\mathbf{3 2}$ \\
\hline Xtend $^{\circledR}$ & $0 \mathrm{Af}$ & 0,74 & 1,52 & 1,72 & 2,43 & 3,52 & 4,82 & 6,24 \\
& & Aef & Cde & Cde & Cd & Cc & Cb & Ca \\
PEBD & \multirow{2}{*}{$0 \mathrm{Ac}$} & 0,08 & 0,14 & 0,24 & 0,31 & 0,75 & 0,71 & 0,31 \\
& & $\mathrm{ABc}$ & $\mathrm{Bbc}$ & $\mathrm{Babc}$ & $\mathrm{Babc}$ & $\mathrm{Ba}$ & $\mathrm{Bab}$ & $\mathrm{Babc}$ \\
Controle & \multirow{2}{*}{$0 \mathrm{Ag}$} & 1,36 & 2,22 & 3,41 & 4,52 & 5,28 & 7,53 & 9,17 \\
& & $\mathrm{Af}$ & Aef & Ade & Acd & $\mathrm{Ac}$ & $\mathrm{Ab}$ & $\mathrm{Aa}$ \\
\hline
\end{tabular}

As médias seguidas ou subscritas de, pelo menos, uma mesma letra maiúscula nas colunas e letra minúscula nas linhas não diferem entre si a $5 \%$ de probabilidade pelo teste de Tukey.

A perda de massa segue uma cinética de ordem zero, correspondendo a uma taxa de desidratação constante ao longo do tempo, que é característica de processos com alta resistência na superfície [26]. O maior percentual de perda de massa observado para o filme Xtend ${ }^{\circledast}$ em relação ao PEBD é, provavelmente, devido à maior permeabilidade ao vapor d'água. O filme Xtend ${ }^{\circledR}$ possui uma taxa de transmissão de vapor d'água superior ao filme de polietileno, possibilitando, conseqüentemente, a redução do teor de umidade no interior dessa embalagem [18].

A taxa de perda de massa dos frutos embalados com PEBD foi 15,7 vezes menor quando comparada com a dos frutos que pertenciam ao controle. Já os frutos embalados com Xtend ${ }^{\circledR}$, apresentaram taxa 1,48 vezes menor. YAMASHITA et al. [26] observaram que a taxa de perda de massa de manga Tommy Atkins embalada com filmes PVC e estocada a $12{ }^{\circ} \mathrm{C}$, foi 3,5 vezes menor do que a dos frutos do controle.
No quarto dia de armazenamento, os frutos embalados com o filme Xtend ${ }^{\circledR}$ perderam $50,4 \%$ da firmeza, enquanto que os frutos embalados com PEBD e os do controle perderam, respectivamente, 59,27 e 83,0\% da firmeza (Tabela 3). Estes resultados podem ser explicados pela menor intensidade de amadurecimento dos frutos devido à supressão parcial de $\mathrm{O}_{2}$ promovida pela baixa permeabilidade do filme. SILVA [24] verificou que mamões embalados com filme de polietileno de baixa densidade e armazenados à temperatura de $10{ }^{\circ} \mathrm{C}$, por um período de armazenamento de 21 dias, perderam, aproximadamente, $45 \%$ da firmeza da polpa em 6 dias de armazenamento.

TABELA 3 - Médias de firmeza (N) em mamões "Golden" acondicionados em dois filmes (Xtend ${ }^{\circledast}, \mathrm{PEBD}$ ) e dos frutos não embalados (controle) em diferentes períodos de armazenamento a $10^{\circ} \mathrm{C}$.

\begin{tabular}{cllllllll}
\hline Embalagens & \multicolumn{7}{c}{ Período de armazenamento (dias) } \\
\cline { 2 - 9 } & \multicolumn{1}{c}{$\mathbf{4}$} & $\mathbf{8}$ & $\mathbf{1 2}$ & $\mathbf{1 6}$ & $\mathbf{2 0}$ & $\mathbf{2 6}$ & $\mathbf{3 2}$ \\
\hline Xtend $^{\circledR}$ & 66,59 & 32,99 & 9,07 & 16,39 & 5,65 & 2,66 & 3,28 & 7,30 \\
& $\mathrm{~A} a$ & $\mathrm{Aab}$ & $\mathrm{Ab}$ & $\mathrm{Ab}$ & $\mathrm{Ab}$ & $\mathrm{Ab}$ & $\mathrm{Ab}$ & $\mathrm{Ab}$ \\
PEBD & 66,59 & 27,12 & 8,88 & 6,86 & 0,99 & 1,82 & 1,20 & 1,77 \\
& $\mathrm{~A} a$ & $\mathrm{ABb}$ & $\mathrm{Ab}$ & $\mathrm{Ab}$ & $\mathrm{Ab}$ & $\mathrm{Ab}$ & $\mathrm{Ab}$ & $\mathrm{Ab}$ \\
Controle & 66,59 & 11,29 & 16,72 & 17,62 & 1,98 & 2,24 & 2,94 & 2,11 \\
& $\mathrm{Aa}$ & $\mathrm{Bb}$ & $\mathrm{Ab}$ & $\mathrm{Ab}$ & $\mathrm{Ab}$ & $\mathrm{Ab}$ & $\mathrm{Ab}$ & $\mathrm{Ab}$ \\
\hline
\end{tabular}

As médias subscritas de, pelo menos, uma mesma letra maiúscula nas colunas e letra minúscula nas linhas não diferem entre si a $5 \%$ de probabilidade pelo teste de Tukey.

Os frutos do controle apresentaram um pequeno incremento de SST somente no final da estocagem (Tabela 4). Este incremento pode ser atribuído à síntese de açúcares que ocorre durante a maturação do mamão [7]. Entretanto, os frutos embalados com os filmes Xtend ${ }^{\circledR}$ e PEBD não apresentaram alteração no conteúdo de sólidos solúveis durante todo o período de estocagem, indicando que a modificação da atmosfera evitou a acumulação final de SST, provavelmente, devido ao retardamento do processo de maturação.

TABELA 4 - Médias do teor de sólidos solúveis totais ( $\left.{ }^{\circ} \mathrm{Brix}\right)$ em mamões "Golden" acondicionados em dois filmes (Xtend ${ }^{\circledR}$, PEBD) e dos frutos não embalados (controle) em diferentes períodos de armazenamento a $10{ }^{\circ} \mathrm{C}$.

\begin{tabular}{lllllllll}
\hline Embalagens & \multicolumn{8}{c}{ Período de armazenamento (dias) } \\
\cline { 2 - 9 } & $\mathbf{0}$ & $\mathbf{4}$ & $\mathbf{8}$ & $\mathbf{1 2}$ & $\mathbf{1 6}$ & $\mathbf{2 0}$ & $\mathbf{2 6}$ & $\mathbf{3 2}$ \\
\hline Xtend $^{\circledR}$ & 11,60 & 12,24 & 11,77 & 11,60 & 12,33 & 11,97 & 12,52 & 12,25 \\
& $\mathrm{Aa}$ & $\mathrm{Aa}$ & $\mathrm{Aa}$ & $\mathrm{Aa}$ & $\mathrm{Aa}$ & $\mathrm{Aa}$ & $\mathrm{Aa}$ & $\mathrm{Ba}$ \\
$\mathrm{PEBD}$ & 11,60 & 11,87 & 11,87 & 12,03 & 12,17 & 12,00 & 11,64 & 11,92 \\
& $\mathrm{Aa}$ & $\mathrm{Aa}$ & $\mathrm{Aa}$ & $\mathrm{Aa}$ & $\mathrm{Aa}$ & $\mathrm{Aa}$ & $\mathrm{Aa}$ & $\mathrm{Ba}$ \\
Controle & 11,60 & 11,85 & 11,90 & 12,07 & 12,31 & 12,33 & 12,27 & 13,57 \\
& $\mathrm{Ab}$ & $\mathrm{Ab}$ & $\mathrm{Ab}$ & $\mathrm{Ab}$ & $\mathrm{Aab}$ & $\mathrm{Aab}$ & $\mathrm{Aab}$ & $\mathrm{Aa}$ \\
\hline
\end{tabular}

As médias subscritas de, pelo menos, uma mesma letra maiúscula nas colunas e letra minúscula nas linhas não diferem entre si a $5 \%$ de probabilidade pelo teste de Tukey.

As medidas de acidez titulável mostraram uma tendência de incremento na fase inicial do armazenamento (Tabela 5), podendo ser devido aos ácidos galacturônicos liberados durante a hidrólise de componentes da parede celular que são responsáveis pela firmeza do tecido [17]. De fato, como mostrado anteriormente, foi observado um amaciamento da polpa dos frutos no inicio da estocagem (Tabela 3).

Os frutos embalados com o filme Xtend ${ }^{\circledR}$ apresentaram uma tendência de acidificação inicial mais lenta, devido à 
menor atividade metabólica indicada pelo amaciamento mais brando e menor acúmulo de $\mathrm{CO}_{2}$, como mostrado na Tabela 1. Segundo DRAETTA et al. [7], o processo de amadurecimento do mamão é sustentado pelo consumo dos ácidos orgânicos uma vez que o fruto não apresenta reservas de amido.

TABELA 5 - Médias da acidez titulável (\% ácido cítrico) e do pH em mamões "Golden" acondicionados em dois filmes (Xtend ${ }^{\circledR}$, PEBD) e dos frutos não-embalados (controle) em diferentes períodos de armazenamento a $10^{\circ} \mathrm{C}$.

\begin{tabular}{|c|c|c|c|c|c|c|c|c|}
\hline \multirow[t]{3}{*}{ Embalagens } & \multicolumn{8}{|c|}{ Acidez Titulável } \\
\hline & \multicolumn{8}{|c|}{ Período de armazenamento (dias) } \\
\hline & $\mathbf{0}$ & 4 & 8 & 12 & 16 & 20 & 26 & 32 \\
\hline \multirow[t]{2}{*}{ Xtend $^{\circledR}$} & 0,07 & 0,09 & 0,09 & 0,06 & 0,05 & 0,08 & 0,08 & 0,08 \\
\hline & Aabc & Aab & $\mathrm{Aa}$ & $A b c$ & $\mathrm{Bc}$ & $\mathrm{Bab}$ & $A a b$ & Babc \\
\hline \multirow[t]{2}{*}{ PEBD } & 0,07 & 0,10 & 0,09 & 0,07 & 0,08 & 0,09 & 0,09 & 0,11 \\
\hline & $A b c$ & Aab & Aabc & Ac & $A b c$ & Babc & Aabc & $\mathrm{Aa}$ \\
\hline \multirow[t]{3}{*}{ Controle } & 0,07 & 0,10 & 0,10 & 0,07 & 0,06 & 0,12 & 0,11 & 0,12 \\
\hline & $A b c$ & Aab & Aab & Abc & $A B c$ & $\mathrm{Aa}$ & $\mathrm{Aa}$ & $\mathrm{Aa}$ \\
\hline & \multicolumn{8}{|c|}{ pH } \\
\hline \multirow[t]{2}{*}{ Xtend $^{\circledR}$} & 6,20 & 6,15 & 5,92 & 6,46 & 6,78 & 6,04 & 6,01 & 6,06 \\
\hline & Aab & Aab & $A b$ & Aab & $\mathrm{Ba}$ & $\mathrm{Bb}$ & $\mathrm{Ab}$ & $\mathrm{Bb}$ \\
\hline \multirow[t]{2}{*}{ PEBD } & 6,20 & 5,95 & 6,11 & 6,43 & 6,52 & 6,00 & 5,75 & 5,54 \\
\hline & $A b$ & Ac & $A b c$ & $\mathrm{Aa}$ & $\mathrm{Aa}$ & $\mathrm{Bbc}$ & Abd & $\mathrm{Ae}$ \\
\hline \multirow[t]{2}{*}{ Controle } & 6,20 & 5,92 & 6,22 & 6,44 & 6,67 & 5,66 & 5,60 & 5,38 \\
\hline & $A c$ & $\mathrm{Ad}$ & $A c$ & $A b$ & $\mathrm{ABa}$ & $\mathrm{Ae}$ & $\mathrm{Ae}$ & Af \\
\hline
\end{tabular}

As médias subscritas de, pelo menos, uma mesma letra maiúscula nas colunas e letra minúscula nas linhas não diferem entre si a $5 \%$ de probabilidade pelo teste de Tukey.

Na Tabela 5, observa-se uma redução pronunciada da acidez entre o oitavo e o décimo sexto dia de estocagem, tanto para os frutos do controle como para aqueles embalados com os filmes Xtend ${ }^{\circledR}$ e PEBD. Entretanto esta redução foi atenuada nos frutos embalados com PEBD, provavelmente, devido à influência da maior concentração de $\mathrm{CO}_{2}$ no interior da embalagem. A diminuição da acidez é devido ao processo de respiração, em que alguns ácidos são utilizados no metabolismo do ciclo de Krebs [14]. Resultados semelhantes foram encontrados por ALMEIDA et al. [2], avaliando a acidez na parte externa do mesocarpo de mamões "Golden" estocados a $13{ }^{\circ} \mathrm{C}$.

Um novo aumento da acidez e redução do pH ocorreu entre o décimo sexto e o vigésimo dia de estocagem, sendo esta variação mais pronunciada nos frutos do controle. Este incremento pode ser devido à intensificação da atividade metabólica característica do pico climatérico do mamão, o que levaria à síntese de ácidos orgânicos [3,13].

No final da estocagem, os frutos embalados com os filmes Xtend ${ }^{\circledR}$ apresentaram os menores conteúdos de acidez e maiores valores de $\mathrm{pH}$. Isto se deve provavelmente à redução da atividade metabólica durante o climatério, provocada pela menor difusividade ao $\mathrm{O}_{2}$. YAMASHITA et al. [26], estudando o efeito de diferentes embalagens de PVC sobre a conservação de mangas, observaram uma minimização do incremento da acidez ao longo da estocagem.

A razão SST/AT é um bom indicador da aceitação sensorial do fruto, sendo mais representativa do que os dados isolados das medidas de açúcares ou da acidez total, uma vez que fornece uma idéia do equilíbrio entre estes dois componentes [5]. Conforme mostrado na Tabela 6, no início da maturação, entre o quarto e oitavo dia de estocagem, ocorreu uma tendência de redução da razão SST/AT em todos os tratamentos devido à tendência de acúmulo de ácidos orgânicos (Tabela 5). Em seguida, ocorreu um aumento desta razão devido ao consumo destes ácidos para sustentar o processo de amadurecimento. Este efeito foi mais acentuado para os frutos embalados com o filme Xtend ${ }^{\circledR}$, atingindo valores máximos em dezesseis dias de estocagem refrigerada. Posteriormente, a razão SST/AT apresentou uma queda expressiva entre dezesseis e vinte dias de estocagem, devido ao novo incremento de acidez da polpa, que foi mais pronunciado nos frutos mantidos sem a embalagem.

No final da estocagem, o aumento expressivo da acidez foi balanceado pelo incremento de SST nos frutos de controle. Os maiores valores da razão SST/AT nos frutos embalados com o filme Xtend ${ }^{\circledR}$ podem ser atribuídos à baixa acidez da polpa, uma vez que os frutos embalados com os filmes plásticos não apresentaram aumento de SST ao final do armazenamento (Tabela 4). Contudo, uma análise sensorial dos frutos é recomendada para caracterizar qualquer alteração de sabor e de odor provocada pela utilização da técnica de modificação da atmosfera.

TABELA 6 - Médias da relação SST/AT em mamões "Golden" acondicionados em dois filmes (Xtend ${ }^{\circledR}$, PEBD) e dos frutos não embalados (controle) em diferentes períodos de armazenamento a $10{ }^{\circ} \mathrm{C}$.

\begin{tabular}{lllllllll}
\hline Embalagens & \multicolumn{8}{c}{ Período de armazenamento (dias) } \\
\cline { 2 - 9 } & $\mathbf{0}$ & $\mathbf{4}$ & $\mathbf{8}$ & $\mathbf{1 2}$ & $\mathbf{1 6}$ & $\mathbf{2 0}$ & $\mathbf{2 6}$ & $\mathbf{3 2}$ \\
\hline Xtend $^{\circledR}$ & 161,3 & 140,7 & 128,4 & 201,9 & 264,8 & 145,23 & 158,2 & 163,7 \\
& $\mathrm{Ab}$ & $\mathrm{Ab}$ & $\mathrm{Ab}$ & $\mathrm{Aab}$ & $\mathrm{Aa}$ & $\mathrm{Ab}$ & $\mathrm{Ab}$ & $\mathrm{Ab}$ \\
PEBD & 164,3 & 118,8 & 135,2 & 175,4 & 161,8 & 142,4 & 135,2 & 105,4 \\
& $\mathrm{Aab}$ & $\mathrm{Abc}$ & $\mathrm{Aabc}$ & $\mathrm{Aa}$ & $\mathrm{Bab}$ & $\mathrm{Aabc}$ & $\mathrm{Aabc}$ & $\mathrm{Bc}$ \\
Controle & 164,3 & 123,9 & 125,1 & 181,1 & 197,9 & 108,8 & 116,2 & 112,7 \\
& $\mathrm{Aab}$ & $\mathrm{Ab}$ & $\mathrm{Ab}$ & $\mathrm{Aa}$ & $\mathrm{Ba}$ & $\mathrm{Ab}$ & $\mathrm{Ab}$ & $\mathrm{Bb}$ \\
\hline
\end{tabular}

As médias subscritas de, pelo menos, uma mesma letra maiúscula nas colunas e letra minúscula nas linhas não diferem entre si a $5 \%$ de probabilidade pelo teste de Tukey.

\section{4 - CONCLUSÕES}

A atmosfera modificada por filmes de PEBD e Xtend ${ }^{\circledR}$-PP7 alterou a atividade metabólica do mamão cv. Golden, minimizando o amolecimento inicial, retardando o incremento de SST e reduzindo a concentração de ácidos orgânicos aos 32 dias de estocagem. Esses efeitos são mais pronunciados nos frutos embalados com o filme Xtend ${ }^{\circledR}$-PP7 que apresentou menor difusividade ao $\mathrm{O}_{2}$ do que o PEBD.

Os frutos embalados com o filme Xtend ${ }^{\circledR}$-PP7 apresentaram os maiores valores da razão SST/AT em 32 dias de estocagem a $10{ }^{\circ} \mathrm{C}$, indicando que eles apresentaram melhor qualidade do que aqueles embalados com PEBD e sem embalagem.

A utilização dos dois filmes plásticos evitou o enrugamento da casca dos mamões ao final de 32 dias de estocagem devido à minimização da perda de água, sendo o PEBD mais efetivo do que o filme Xtend ${ }^{\circledR}$-PP7. 


\section{5 - REFERÊNCIAS BIBLIOGRÁFICAS}

[1] AL-ATI, T.; HOTCHKISS, J. H. The role of packaging film permeselectivity in modified atmosphere packaging. Journal of Agricultural and Food Chemistry, v. 51, n. 14, p. 4133-4138, 2003.

[2] ALMEIDA, R. F.; MARTINS, M. L. L.; RESENDE, E. D.; VITORAZI, L.; CARLOS, L. A.; PINTO, L. K. A. Influência da temperatura de refrigeração sobre as características químicas do mamão cv. 'Golden `. Ciência de Tecnologia de Alimentos, v. 26, n. 3, p. 577-581, 2006.

[3] AN, J.; PAULL, R.E. Storage and ethylene influence on ripening of papaya fruit. J. Amer. Soc. Hort. Sci., v. 115, n. 6, p. 949-953, 1990.

[4] AOAC - Association of official analytical chemistry Oficial methods of analyses of the Association of Official Analytical Chemistry. $11^{\circ}$ Edição. Washington, 1998.

[5] ChitarRa, M. I. F.; ChitarRA, A. B. Pós-colheita de frutas e hortaliças. Fisiologia e manuseio. Lavras, $1^{\circ}$ edição, ESAL/FAEPE, 1990.

[6] CISNERO - ZEVALLOS L.; KROCHTA J. M. Internal modified atmosphere of coated fresh fruit and vegetables: Understanding relative humidity effects. Journal of Food Science, v. 67, n. 8, p. 2792-2797, 2002.

[7] DRAETTA, I. dos S.; SHIMOKAMI, M.; YOKOMIZO, Y.; FUJITA, J. T.; MENEZES, H. C.; BLEINORITH, E. W. Transformações bioquímicas do mamão (Carica papaya L.) durante a maturação. Coletânea do Instituto de Tecnologia de Alimentos, v. 6, n. 2, p. 395-408, 1975.

[8] GONZÁLEZ-AGUILAR, G. A.; BUTA, J. A.; WANG, C. Y. Methyl jasmonate and modified atmosphere packaging (MAP) reduce decay and maintain post-harvest quality of papaya "Sunrise". Postharvest Biology and Technology, v. 28, n. 3, p. 361-370, 2003.

[9] HOTCHKISS, J. H.; BANCO, M. J. Influence of new packaging technologies on the growth of microorganism in produce. Journal of Food Protection, v. 55, n. 10, p. 815-820, 1992.

[10] JACOMINO A. P.; KUGLE, R. A.; SARANTOPOULOS, C. I. G.; SIGRIST, J. M. M. Evaluation of plastic packages for Guava refrigerated preservation. Packaging Technology and Science, v. 14, n. 1, p. 11-19, 2001.

[11] JIANG, Y.; JOYCE, D. C.; MACNISH, A. J. Extension of the shelf life of banana fruit by 1-methylcyclopropene in combination with polyethylene. Postharvest Biology and Technology, v. 16, n. 2, p. 187-193, 1999.

[12] KOSKI, D. V. Is current modified/controlled atmosphere packaging technology applicable to U. S. food market? Food Technology, v. 42, n. 9, p. 54-54, 1998.

[13] LAZAN, H.; MOHD. ALI, Z.; LIANG, K.S. and YEE, K.L. Polygalacturonase activity and variation in ripening of papaya fruit with tissue depth and heat treatment. Physiologia Plantarum, v. 77, n. 1, p. 93-98, 1989.

[14] LEHNINGER, A. L.; NELSOM, D. L.; COX, M. M. Ciclo do ácido cítrico In: Lodi, W. R.; Simões A. A. (tradutores). Princípios de Bioquímica. São Paulo: Savier,1995. Cap. 15, p. 331-354.

[15] MEDINA, V. M.; OLIVEIRA, J. R. P. Colheita e póscolheita In: Mamão. Produção: aspectos técnicos.
Embrapa Mandioca e Fruticultura, Brasília: Embrapa comunicação para transferência de tecnologia, 2000.

[16] MOLEYAR, V.; NARASIMHAM, P. Modified atmosphere packaging of vegetables- an appraisal- Journal of Food Science and Technology, v. 31, n. 4, p. 267-278, 1994.

[17] PAULL, R. E.; GROSS, K.; QIU, Y. Changes in papaya cell walls during fruit ripening. Postharvest Biology and Technology, v. 16, n. 1, p. 79-89, 1999.

[18] PESIS, E.; AHARONI, D.; AARÓN, Z.; BEN-ARIE, R.; AHARONI, N.; Fuchs, Y. Modified atmosphere and modified humidity packaging alleviates chilling injury symptoms in mango fruit. Postharvest Biology and Technology, v. 19, n. 1, p. 93-101, 2000.

[19] PINTO, L. K. A. Efeito de diferentes filmes plásticos aplicados na conservação de mamão (Carica papaya L.) cultivar Golden sob refrigeração, Campos dos Goytacazes, 2003, 117 f. Dissertação (Mestrado em Produção Vegetal), Universidade Estadual do Norte Fluminense Darcy Ribeiro (UENF).

[20] PORAT, R.; WEISS, B.; COHEN, L.; DAUS, A.; AHAONI, N. Reduction on postharvest rind disorders in citrus fruit by modified atmosphere packing. Postharvest Biology and Technology, v. 33, n. 1, p. 35-43, 2004.

[21] RAI, D. R.; OBEROI, H. S.; BABOO, B. Modified atmosphere packaging and its effect on quality and shelf-life of fruits and vegetables - An overview. Journal of Food Science and Technology, v. 39, n. 3, p. 199-207, 2002.

[22] RESENDE, E. D.; CARLOS, L. A.; VITORAZI, L.; OLIVEIRA, V. V. Desenvolvimento e avaliação de uma metodologia de amostragem de frutos de mamoeiro (Carica papaya L.). In: CD-ROM. I Reunião de Pesquisa do Frutimamão no Norte Fluminense, 2003, Campos dos Goytacazes, 2003.

[23] RODOV, V.; HOREV, B.; VINOKUR, Y.; COPEL, A.; AHARONI, Y.; AHARONI, N. Modified-atmosphere packaging improves keeping quality of Charentais-types melons. Hortscience, v. 36, n. 6, p. 50-953, 2002.

[24] SILVA, E. O. Efeito da embalagem plástica e da temperatura sobre a qualidade pós-colheita do mamão. Viçosa, 1995, 65p. Dissertação (Mestrado em Fitotecnia), Universidade Federal de Viçosa (UFV).

[25] SILVA, H. R. F.; RESENDE, E. D.; VITORAZI, L.; PINTO L. K. A.; MARTINS, M. L. L. Relação entre o escurecimento e atividade da enzima fenilalanina amonialiase em mamão (Carica papaya L.) armazenado sob refrigeração. In: PAPAYA BRASIL, Qualidade do mamão para o mercado interno. 2003, Vitória, Incaper, p. 681-684.

[26] YAMASHITA, F.; TONZAR, A. M. C.; FERNÁNDEZ, J. G.; MORYA, S.; BENASI, M. T. Embalagem individual de mangas cv Tommy Atkins em filme de plástico: efeito sobre a vida de prateleira. Revista Brasileira de Fruticultura, v. 23, n. 2, p. 288-292, 2001.

\section{6 - AGRADECIMENTOS}

Os autores agradecem à FAPERJ, à FINEP e ao MCT/ CNPq pelo auxílio financeiro e à Caliman Agrícola S. A. pela parceria de pesquisa no Projeto Frutimamão. 